\title{
Síndrome de Congestão Pélvica: Tratamento Endovascular
}

\author{
Bez LG. ${ }^{1}$, Silva CMO. ${ }^{1}$ \\ ${ }^{1}$ Belo Horizonte - Belo Horizonte. \\ E-mail: lgbez@terra.com.br
}

Bez, L.G.; Silva, C.M.O. 2013. Síndrome de Congestão Pélvica: Tratamento Endovascular, p.73. In: Bastos, Francisco Reis. Anais do V Simpósio Internacional de Flebologia [Blucher Medical Proceedings n.1 v.1]. São Paulo: Blucher, 2014

http://dx.doi.org/10.5151/medpro-flebo-SIF_46
A Síndrome de Congestão Pélvica é uma condição pouco conhecida em nosso meio. É responsável por uma porcentagem significativa de pacientes com dor pélvica crônica sem diagnóstico específico. Trata-se do correspondente feminino da varicocele, descrito pela primeira vez por Richet, em 1957.

A fisiopatologia da síndrome é explicada pelo refluxo na veia gonadal, seja por incompetência valvar ou por obstrução mecânica, como ocorre no "Fenômeno de Quebra-Nozes". Também são responsáveis pela dor pélvica, as próprias varizes.

Não existe acordo quanto aos critérios que devem ser adotados para o diagnóstico da síndrome. Enquanto alguns autores se baseiam apenas em achados do exame clínico, preferimos confiar nos dados da ultrassonografia, quando é detectado aumento do fluxo sanguíneo nas veias gonadais e nas varizes pélvicas com realização da manobra de Valsalva.

Alguns achados clínicos corroboram o diagnóstico: presença de varizes na raiz das coxas que reaparecem após o tratamento cirúrgico, presença de varizes vulvares e nos glúteos, sensação de peso ou edema pélvico, que aparecem ou pioram com ortostatismo prolongado.

O padrão ouro permanece sendo a flebografia intra-operatória, com documentação do refluxo do contraste pela veia gonadal, enchendo as varizes, na presença de dilatação desses vasos.

Realizamos o tratamento com espuma de polidocanol e molas de Gianturco, com excelente resultado até o momento. Preferimos a via transfemoral à jugular, que foi usada apenas no primeiro caso. Realizamos de rotina flebografia das veias ilíacas internas, que ocasionalmente podem ser responsáveis pelas varizes pélvicas, ou podem mantê-las por circulação colateral. Caso isso seja comprovado, esses vasos também são embolizados.

Os estudos que foram realizados até o momento não são comparáveis, seja pela discrepância nos critérios diagnósticos, seja pela técnica utilizada para o tratamento. Torna-se, portanto, necessária a realização de mais estudos, mantendo os critérios já adotados nas principais séries, de maneira a uniformizar os dados e possibilitar a comparação entre eles.

Palavras-chave: síndrome congestão pélvica, varizes pélvicas, varizes vulvares, varizes glúteas. 